\title{
IONIC AND ELECTRONIC CONDUCTION IN $\beta-\mathrm{PbF}_{2}$
}

\author{
J. Schoonman, G.A. Korteweg and R.W. Bonne \\ Solid State Department, Physical Laboratory, University of Utrecht, Utrecht, The Netherlands
}

(Received 4 September 1974 by A.R. Miedema)

\begin{abstract}
$\beta-\mathrm{PbF}_{2}$ is an extrinsic $n$-type semiconductor at temperatures below $300 \mathrm{~K}$. The contribution of lattice defects to the electrical conductivity increases rapidly above room temperature. Polarization studies using a Wagner-cell indicate that above $350 \mathrm{~K}$ ionic conductivity becomes predominant in undoped $\beta-\mathrm{PbF}_{2}$ crystals.
\end{abstract}

\section{INTRODUCTION}

RECENTLY we have started an investigation into the electrical conductivity of $\mathrm{PbFCl}$. This mixed lead halide can be prepared by melting stoichiometric amounts of $\mathrm{PbF}_{2}$ and $\mathrm{PbCl}_{2}{ }^{1,2} \mathrm{~A}$ comparison has been made with the conductivity behavior of $\beta \cdot \mathrm{PbF}_{2}$ and $\mathrm{PbCl}_{2}$ single crystals. ${ }^{1}$

$\mathrm{PbCl}_{2}$ shows predominantly anion conduction via anion vacancies. The electronic component of the electrical conductivity of $\mathrm{PbCl}_{2}+1$ per cent $\mathrm{KCl}$ has been measured by Wagner and Wagner, ${ }^{3}$ using a polarization cell of the type

$$
(\rightarrow) \mathrm{Pb} / \mathrm{PbCl}_{2}-\mathrm{KCl} / \mathrm{C}(+)
$$

For a voltage of $0.2 \mathrm{~V}$, these authors found the ratio of the electronic current ( $p$-type) to the total current to be $10^{-4}$ at $573 \mathrm{~K}$. Lead fluoride, however, is an extrinsic semiconductor. ${ }^{4.5}$ In the temperature region 200-300 K Arkhangel'skaya et al. ${ }^{4}$ measured predominantly $n$-type electronic conductivity in undoped $\beta-\mathrm{PbF}_{2}$ and in crystals doped with trivalent rare earth ions. The activation energy for conduction in this temperature region turned out to be $\sim 0.8 \mathrm{eV}$ for all crystals. The trivalent dopes increased the $n$-type electronic conductivity. ${ }^{4}$ In a previous paper ${ }^{1}$ the a.c.electrical conductivity of undoped $\beta-\mathrm{PbF}_{2}$ single crystals was presented (temperature region 300 $680 \mathrm{~K}$ ). In the temperature region $300-420 \mathrm{~K}$ the conductivity activation enthalpy has the value of $0.70 \mathrm{eV}$. Recently, Kennedy et al. ${ }^{9}$ obtained for the conductivity enthalpy of single crystals the value $0.60 \mathrm{eV}$ from a.c.-conductivity measurements, and from d.c.-conductivity measurements the value $0.65 \mathrm{eV}$. This enthalpy has been correlated with fluoride ion vacancy migration. ${ }^{1,9}$ Moreover, on using cell arrangement I with applied d.c.-voltages larger than $1.0 \mathrm{~V}$, Kennedy et al. measured $p$-type electronic conductivity in $\beta-\mathrm{PbF}_{2}$. The electronic conductivity represents at most $10^{-4}$ per cent of the total conductivity at $423 \mathrm{~K}$.

As regards the results reported by Arkhangel'skaya et $a l .{ }^{4}$ and the results reported by Kennedy et al. ${ }^{9}$ the electronic conductivity behavior of $\beta-\mathrm{PbF}_{2}$ would show a gradual change from $n$-type to $p$-type conductivity, whereas the magnitude of the electronic component of the electrical conductivity would decrease at increasing temperature in the region $300-420 \mathrm{~K}$.

The present paper deals with polarization studies performed on $\beta-\mathrm{PbF}_{2}$ single crystals in the temperature region $325-410 \mathrm{~K}$ using cell arrangement $\mathrm{I}$.

\section{EXPERIMENTAL}

A detailed description of the measuring method, and the electrode contacts has been given elsewhere. ${ }^{6}$ The results of this study were obtained with electrode contact (c) from reference 6. Single crystals of $\beta-\mathrm{PbF}_{2}$ 
were kindly placed at our disposal by Dr. E.E. Schneider of the University of Newcastle-upon-Tyne. These crystals were grown by Gulton Industries from BDH zone-refined Optran Material. ${ }^{8}$

\section{THEORY}

The total electronic current, $i_{e}$, through an ionic conductor with one reversible and one inert electronically conducting electrode can be expressed by

$$
\begin{aligned}
i_{e}=i_{n}+i_{p}= & \frac{k T}{e L}\left\{\sigma_{n}^{0}[1-\exp (-e E / k T)]+\right. \\
& \left.\sigma_{p}^{0}[\exp (+e E / k T)-1]\right\} .
\end{aligned}
$$

$L$ denotes the cell constant (ratio of crystal thickness to electrode area), $\sigma_{n}^{0}$, and $\sigma_{p}^{0}$ are the specific electronand electron hole conductivities for lead fluoride in contact with metallic lead $\left(a_{\mathrm{Pb}}=1\right) .{ }^{7} E$ denotes the applied d.c.-voltage, whereas $e, k$ and $T$ have their usual meaning. In the case $\sigma_{n}^{0} \gg \sigma_{p}^{0}$ the current-voltage curve will show at low voltages a saturation current,

$$
i_{n}=\frac{k T}{e L} \sigma_{n}^{0}
$$

which depends in the extrinsic region of the conductivity on the purity of the crystal. An exponentially increasing current shows conduction by electron holes.

As regards cell arrangement I we can write under the assumption that the thermal defects in $\beta-\mathrm{PbF}_{2}$ are generated according to an anion Frenkel mechanism

$\mathrm{Pb}(s)+2 F_{i}^{\prime}=\mathrm{PbF}_{2}+2 V_{i}^{x}+2 e^{\prime}, K_{1}=n^{2} /\left[F_{i}^{\prime}\right]^{2}$

or,

$$
\mathrm{Pb}(s)=\mathrm{Pb}_{\mathrm{Pb}}^{x}+2 V_{F}^{*}+2 e^{\prime}, K_{2}=n^{2}\left[V_{F}^{*}\right]^{2}
$$

with

$$
K_{F}^{2}=K_{1}^{-1} K_{2}
$$

$K_{F}\left(=\left[F_{i}^{\prime}\right]\left[V_{F}^{*}\right]\right)$ being the equilibrium constant for intrinsic defect formation in lead fluoride.

Monovalent cations at lead ion sites, $\mathrm{Me}_{\mathrm{Pb}}^{\prime}$, increase the concentration of fluoride ion vacancies, whereas trivalent cations, $\mathrm{Me}_{\mathrm{Pb}}$, increase the interstitial fluoride ion concentration. ${ }^{5}$ The total electroneutrality condition valid for the extrinsic region of an undoped crystal with mixed ionic and electronic conduction reads

$$
Y+\left[F_{i}^{\prime}\right]+n=\left[V_{F}^{*}\right]+p
$$

where $Y\left(=\left[\mathrm{Me}_{\mathrm{Pb}}^{\prime}\right]-\left[\mathrm{Me}_{\mathrm{Pb}}^{\cdot}\right]\right.$ denotes the remaining impurity content. From this relation we obtain with the intrinsic electronic equilibrium constant $K_{i}(=n p)$, and the equilibrium constants (3) and (4) for $n$

$$
\begin{aligned}
& n=\left(K_{1}^{-1 / 2}+1\right)^{-1}\left\{-\frac{1}{2} Y+\left[\frac{1}{4} Y^{2}+K_{F}+K_{2}^{1 / 2}+\right.\right. \\
& \left.\left.K_{i}\left(K_{1}^{-1 / 2}+1\right)\right] 1 / 2\right\}
\end{aligned}
$$

which reduces for electron conduction in a predominantly ionic conductor to

$$
\begin{aligned}
n= & \left(K_{1}^{-1 / 2}+1\right)^{-1}\left\{-\frac{1}{2} Y+\left[\frac{1}{4} Y^{2}+\right.\right. \\
& \left.\left.K_{F}\left(1+K_{1}^{1 / 2}\right)\right] 1 / 2\right\} .
\end{aligned}
$$

This relation shows that $n$ decreases upon doping with monovalent cations, $Y>0$, and that $n$ increases upon doping with trivalent cations, $Y<0$.

\section{RESULTS AND DISCUSSION}

The a.c.-electrical conductivities of the $\beta-\mathrm{PbF}_{2}$ single crystals with Aquadag-electrodes were in agreement with previously published conductivities at $1 \mathrm{kC}$.

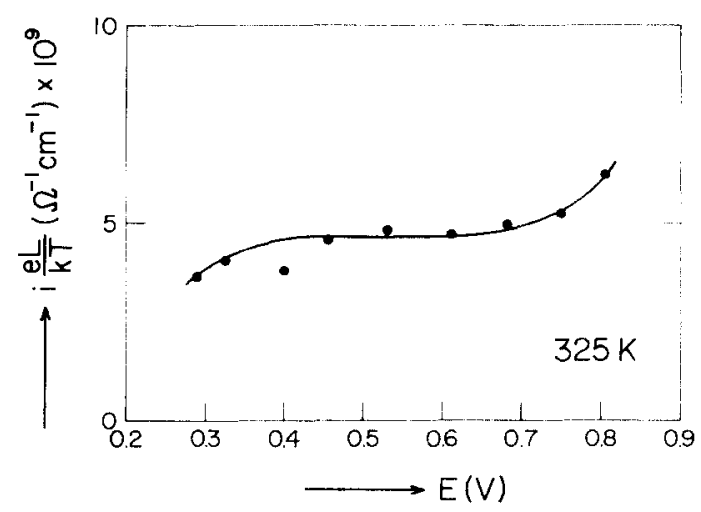

FIG. 1. The electronic current in a $\beta-\mathrm{PbF}_{2}$ single crystal $\sigma_{n}^{0}=4.7 \times 10^{-9} \Omega^{-1} \mathrm{~cm}^{-1}$.

The magnitude of the conductivity for the undoped specimens showed differences of at most 18 per cent in the temperature region $325-410 \mathrm{~K}$, probably due to different values for $Y$. In this temperature region we obtained for voltages from 0.2 up to $1.0 \mathrm{~V}$ plateautype current-voltage characteristics, indicating 
Table 1. Electron and total conductivities in $\beta-P b F_{2}$ crystals

\begin{tabular}{cccc}
\hline$T(\mathrm{~K})$ & $\sigma_{n}^{0}\left(\Omega^{-1} \mathrm{~cm}^{-1}\right)$ & $\sigma_{t}\left(\Omega^{-1} \mathrm{~cm}^{-1}\right)$ & $t_{n}$ \\
\hline 325 & $4.7 \times 10^{-9}$ & $1.20 \times 10^{-7}$ & $3.9 \times 10^{-2}$ \\
325 & $4.5 \times 10^{-9}$ & $1.20 \times 10^{-7}$ & $3.8 \times 10^{-2}$ \\
327 & $4.5 \times 10^{-9}$ & $1.33 \times 10^{-7}$ & $3.4 \times 10^{-2}$ \\
347 & $5.0 \times 10^{-9}$ & $5.50 \times 10^{-7}$ & $9.1 \times 10^{-3}$ \\
351 & $8.0 \times 10^{-9}$ & $7.16 \times 10^{-7}$ & $1.1 \times 10^{-2}$ \\
410 & $5.4 \times 10^{-8}$ & $1.69 \times 10^{-5}$ & $3.2 \times 10^{-3}$ \\
\hline
\end{tabular}

conduction by electrons. In Fig. 1 we have plotted the electronic current as $i(e L / k T)$ vs $E$, the applied voltage, in a $\beta-\mathrm{PbF}_{2}$ crystal at $325 \mathrm{~K}$, whereas in Table 1 conductivity data for undoped $\beta-\mathrm{PbF}_{2}$ are tabulated. A plot of $\log \sigma_{n}^{0}$ vs $T^{-1}$ leads to an estimate for the conduction activation enthalpy of $0.38 \mathrm{eV}$.

Kennedy et al. ${ }^{\mathbf{9}}$ measured an exponential increase in the current, indicating conduction by electron holes, in the voltage region $1.0-1.6 \mathrm{~V}$. The magnitude of the electron hole currents, expressed as $i(e L / k T)$ is larger than $10^{-7} \Omega^{-1} \mathrm{~cm}^{-1}$. These values are well above the plateau conductivities gathered in Table 1 . The specific electron hole conductivity, $\sigma_{p}^{\circ}$, is at $423 \mathrm{~K}$ approximately three orders of magnitude smaller than $\sigma_{n}^{0}$. A machine calculation of the current-voltage curve, described by equation (1), shows that for $\sigma_{n}^{0}>10^{3} \sigma_{p}^{0}$ a saturation current occurs at lower voltages.

The total a.c.-conductivity, $\sigma_{t}$, has been measured at $1 \mathrm{kC}$, and actually stands for the parallel conductance of the samples. $\sigma_{n}^{0}$ represents a series conductance. The conductivity of $\beta-\mathrm{PbF}_{2}$ is strongly frequency dependent. ${ }^{9}$ This means that the zero frequency conductance has to be obtained from admittance plots in order to obtain more accurate transference numbers. The $\sigma_{t}$ and $t_{n}$ values, as introduced in Table 1 , are intended merely to illustrate the decreasing contribution of the electronic conductivity to the total conductivity.

The present data show that in the temperature region $325-410 \mathrm{~K}$, and at voltages below $1.0 \mathrm{~V}$ conduction by electrons, rather than electron holes, is predominant in a Wagner-polarization arrangement like cell I. The scatter in $\sigma_{n}^{0}$ values at lower temperatures may well be caused by differences in $Y$. For a quantitative check of relation ${ }^{7}$ a doping study with aliovalent impurities is necessary.

Acknowledgement - The authors are indebted to Prof. Dr. G. Blasse for critical discussions during the preparation of the manuscript.

\section{REFERENCES}

1. SCHOONMAN J., DIRKSEN G.J. and BLASSE G., J. Solid State Chem. 7, 245 (1973).

2. SCHOONMAN J., HALFF A.F. and BLASSE G., Solid State Commun. 13, 677 (1973).

3. WAGNER J.B. and WAGNER C., J. Electrochem. Soc. 104, 509 (1957).

4. ARKHANGEL'SKAYA V.A., EROFEICHEV V.G. and KISELEVA M.N., Sov. Phys. Solid State 14, 2953 (1973).

5. CHAN K.K. and SHIELDS L., J. Phys. C(Solid State Phys.) 2, 1978 (1969).

6. SCHOONMAN J. and MACKE A.J.H., J. Solid State Chem. 5, 105 (1972).

7. WAGNER C., Z. Elektrochem. 60, 4 (1956).

8. SCHNEIDER E.E., (private communication).

9. KENNEDY J.H., MILES R. and HUNTER J., J. Electrochem. Soc. 120, 1441 (1973).

$\beta-\mathrm{PbF}_{2}$ ist ein extrinsiker Halbleiter für Temperaturen unter $300 \mathrm{~K}$. Der Beitrag von Gitterdefekten zu der elektrischer Leitfähigkeit nimmt schnell zu über Zimmertemperatur. Untersuchungen der Polarisation einer Wagnerzelle weissen auf, dass uber etwa $350 \mathrm{~K}$ die Leitfähigkeit in undotierten $\beta-\mathrm{PbF}_{2}$ Kristallen überwiegend ionisch wird. 